\title{
IMPACTO DA CONFORMIDADE FINANCEIRA E FISCAL SOBRE O GERENCIAMENTO DE RESULTADOS
}

\author{
Géssica Cappellesso' \\ Jomar Miranda Rodrigues ${ }^{2}$ \\ Rodrigo de Souza Gonçalves ${ }^{3}$
}

Resumo: Este estudo teve por objetivo investigar o impacto da conformidade financeira e fiscal (CFF) sobre o gerenciamento de resultados por meio de accruals, levando em consideração países common e code law do Grupo dos Vinte (G-20). Para tal, foram utilizadas 26 nações ao longo de 2006 a 2016, onde se realizou uma análise a nível país e se seguiu três etapas: construção de um índice de gerenciamento de resultados para cada país e ano, desenvolvimento de uma medida de CFF para os países-anos, e associação entre as medidas obtidas. Como resultados, constatou-se uma associação negativa entre o índice de gerenciamento de resultados e o nível de CFF dos países, o que sugere que a maior proximidade entre as normas contábeis e fiscais reduz os incentivos para a manipulação dos números contábeis. Contudo, também foi verificado que essa relação difere entre nações que adotaram ou não as IFRS, sendo observado que, em países que realizaram a convergência, a maior CFF esteve associada a um aumento no índice de gerenciamento de resultados. Portanto, esse resultado demonstra a importância de se considerar os efeitos de variáveis institucionais ao avaliar a relação entre CFF e gerenciamento de resultados.

Palavras-chave: Conformidade Financeira e Fiscal; Gerenciamento de Resultados; IFRS; Common Law; Code Law.

\footnotetext{
gessica_cappellesso@hotmail.com - Universidade de Brasília-DF. Brasil. https://orcid.org/0000-0002-4684-7376

2jomar@unb.br - Universidade de Brasília-DF. Brasil. https://orcid.org/0000-0001-5961-243X

rgoncalves@unb.br - Universidade de Brasília-DF. Brasil. https://orcid.org/0000-0003-3768-2968

- DOI: http://dx.doi.org/10.14392/asaa.2019120102

- Artigo foi apresentado no XII Congresso ANPCONT realizado em Joăo Pessoa/PB nos dias de 09 a 12 de junho de 2018.

- Artigo submetido em: 06/12/2018. Aceito em: 08/05/2019.
} 


\title{
THE IMPACT OF BOOK-TAX CONFORMITY ONEARNINGS MANAGEMENT
}

\begin{abstract}
This study aimed to investigate the influence of book-tax conformity (BTC) on accruals earnings management, taking into consideration G-20 code law and common law countries. To this end, it was used 26 nations throughout 2006 to 2016, where a country level analysis was performed, and three steps were followed: the construction of an earnings management index for each country and year; the development of a BTC measure for the countries-years; and the association between these measures. As results, it was observed a negative association between the earnings management index and the BTC level of the countries, suggesting that closer proximity between financial and tax rules reduces the incentives for earnings manipulation. However, it was also observed that this association differs from IFRS adopters and non-adopters, as it was detected that in IFRS adopters great BTC was associated with higher earnings management. Therefore, this result demonstrates the importance of considering the effects of institutional variables when assessing the BTC and earnings management relation.
\end{abstract}

Keywords: Book-Tax Conformity; Earnings Management; IFRS; Common Law; Code Law. 


\section{INTRODUÇÃO}

C om a implementação das International Financial Reporting Standards (IFRS), alguns países acabam passando de uma contabilidade com base na legislação fiscal para um sistema financeiro e fiscal mais independente, o que resulta na redução do nível de conformidade financeira e fiscal das nações (Tang, 2014).

De acordo com Atwood, Drake e Myers (2010), a conformidade financeira e fiscal (CFF) pode ser entendida como a flexibilidade que uma empresa tem para divulgar um lucro tributável que é diferente do lucro contábil. Mais ainda, a CFF pode ser caracterizada pela vinculação entre as normas financeiras e fiscais e, consequentemente, pela proximidade entre o lucro contábil e o tributável (Hanlon, Laplante, \& Shevlin, 2005).

Dessa forma, a CFF é determinada no nível país, uma vez que cada nação possui seu próprio conjunto de normas contábeis e fiscais, as quais podem ser mais ou menos próximas. Por exemplo, nos Estados Unidos da América (EUA), observa-se um baixo nível de CFF, pois as regras para determinar os lucros contábil e tributável são separadas (Hanlon \& Shevlin, 2005). Já no Brasil, essa conformidade seria mais elevada, visto que o país era conhecido por ter forte influência fiscal sobre as normas contábeis (Niyama, Costa, \& Aquino, 2005).

A proximidade entre a legislação fiscal e os padrões contábeis é um dos fatores que impactam significativamente o desenvolvimento contábil dos países (Choi \& Meek, 2011). Assim, pode-se dizer que a estrutura fiscal-financeira adotada em uma nação é capaz de influenciar as práticas contábeis utilizadas pelas empresas e as decisões de divulgação dos gestores. Logo, é possível que a prática de gerenciamento de resultados das empresas seja impactada pelo nível de CFF exigido em um país.

De um lado, os defensores da CFF argumentam que uma maior ligação entre as normas financeiras e fiscais reduziria o nível de gerenciamento de resultados (GR), à medida que a discricionariedade dos gestores seria restringida e os custos de seu oportunismo seriam elevados (Blaylock, Gaertner, \& Shevlin, 2015).

Para Desai (2005) e Frank, Lynch e Rego (2009), os gestores exploram as diferenças existentes entre os relatórios contábeis e fiscais de maneira oportunista, dado que a lacuna entre as normas financeiras e tributárias dão a oportunidade de gerenciar o lucro contábil para cima e o lucro tributável para baixo em um mesmo período de divulgação.

Portanto, ao elevar a CFF, os incentivos para a divulgação oportunista seriam restringidos, uma vez que o gerenciamento para aumentar o resultado contábil seria seguido por maiores impostos, e o gerenciamento para reduzir o lucro tributável seria acompanhado por um lucro contábil menor, o que não iria ao encontro dos interesses dos investidores (Blaylock, Gaertner, \& Shevlin, 2015). Assim, países com maior proximidade entre o lucro contábil e o tributável forneceriam menos incentivos para as práticas de elisão fiscal e GR (Desai, 2005).

Por outro lado, os críticos da CFF acreditam que a maior proximidade entre as normas financeiras e fiscais pode resultar num aumento do GR, devido à perda de informação. Especificamente, ao aproximar o lucro contábil e o tributável, a book-tax differences - que é um indicador de GR e de agressividade fiscal - seria reduzida, o que restringiria a capacidade dos outsiders de identificar a manipulação (Tang, 2005; Blaylock, Gaertner, \& Shevlin, 2015). Além disso, a perda de informação gerada pela maior CFF 
também pode levar a maior suavização de resultados, devido às motivações tributárias (Blaylock, Gaertner, \& Shevlin, 2015).

Nesse contexto, é possível observar que o assunto é controverso à medida que há estudos condizentes com a CFF restringindo o GR (Burgstahler, Hail, \& Leuz, 2006; Watrin, Ebert, \& Thomsen, 2014; Blaylock, Gaertner, \& Shevlin, 2015) e outros afirmando que há um aumento na manipulação dos resultados (Tang, 2014).

Ainda, deve-se considerar que o nível de CFF exigido num país pode ter ligação com suas características institucionais, como a origem legal, o que pode afetar sua relação com o GR. Em países common law, por exemplo, existe uma maior separação entre a contabilidade financeira e fiscal, enquanto que países code law apresentam maior CFF, devido à forte interferência governamental nas normas contábeis (Ball, Kothari, \& Robin, 2000; Choi \& Meek, 2011).

Então, considerando que a maior CFF pode elevar ou reduzir o GR, e que a origem legal é uma característica institucional capaz de influenciar esse comportamento, levanta-se a seguinte questão de pesquisa: Qual o impacto da conformidade financeira e fiscal sobre o nível de gerenciamento de resultados dos países common law e code law? Portanto, realiza-se uma análise a nível-país, com o objetivo de investigar o impacto da conformidade financeira e fiscal sobre o GR por meio de accruals, levando em consideração países common e code law do Grupo dos Vinte (G-20).

Essa questão é relevante para órgãos reguladores e normatizadores, pois trata dos custos e benefícios da CFF, contribuindo para suas decisões e formulações. Também é importante para investidores, visto que sua tomada de decisão é feita com base nas informações divulgadas, e essas podem ser mais ou menos gerenciadas dependendo do nível de CFF de um país. Por fim, o estudo também contribui para o avanço da literatura de CFF e GR, cuja relação ainda é controversa (Blaylock, Gaertner, \& Shevlin, 2015).

\section{REFERENCIAL TEÓRICO E EMPÍRICO}

\subsection{Conformidade Financeira e Fiscal e Gerenciamento de Resultados}

O nível de conformidade financeira e fiscal varia entre os países, havendo alguns onde a legislação tributária determina os padrões contábeis, e outros onde a contabilidade financeira e fiscal é mais independente (Choi \& Meek, 2011). Nesse sentido, Lamb, Nobes e Roberts (1998) sugerem cinco graus de conformidade entre as regras contábeis e financeiras:

I. Desconexão: falta de influência da legislação fiscal sobre a divulgação financeira;

II. Identidade: as regras contábeis e tributárias são as mesmas.

III. Liderança contábil: a regra de divulgação financeira é seguida para propósitos de divulgação financeira e fiscal.

IV. Liderança fiscal: a norma fiscal é escolhida para propósitos tributários e financeiros.

V. Domínio fiscal: as regras de divulgação financeira são ignoradas, e a norma fiscal é seguida para fins fiscais e financeiros.

No Brasil, por exemplo, as regras fiscais eram as responsáveis por influenciar as normas societárias, mesmo que de forma indireta (Niyama, Costa, \& Aquino, 2005; Costa, 2012). Mas, após a adoção das IFRS, as empresas começaram a demonstrar um maior distanciamento entre os lucros contábil e tributável, indicando a redução da influência da legislação tributária sobre as normas contábeis e um menor nível de CFF (Costa, 2012). Assim, os contadores passaram a ter maior liberdade na divulgação do lucro tribu- 
tável, o que possibilitou mais práticas de elisão fiscal para minimizar o lucro tributável sem que o lucro contábil fosse também reduzido (Kajimoto \& Nakao, 2018).

Em outras nações, essa liberdade pode ser ainda maior, como é o caso dos EUA. Nesse país, as empresas mantêm dois conjuntos de relatórios separados, um que divulga o lucro contábil para o mercado de capitais, e outro que reporta o lucro tributável para o governo (Desai, 2005). Logo, os contadores devem preparar duas medidas de resultado distintas: o lucro contábil com base nos PCGA, e o lucro tributável conforme o Internal Revenue Code (IRC) (Hanlon \& Shevlin, 2005). O mesmo ocorre na Austrália, cujas empresas devem seguir regras separadas para determinação do lucro contábil e do lucro tributável (Tran \& Yu, 2008).

Esses países que possuem uma dualidade de conjuntos (isto é, onde os sistemas fiscal e financeiro são independentes) concedem aos gestores ainda mais liberdade na determinação das medidas de resultado. Isso permite que eles possam vir a divulgar um lucro contábil elevado para o mercado de capitais, ao mesmo tempo em que reportam um lucro tributável mais reduzido para as autoridades tributárias (Desai, 2005; Frank, Lynch, \& Rego, 2009).

Nesse sentido, a literatura sugere que a interferência da legislação tributária nas normas, por meio da exigência de maior CFF, poderia aumentar a transparência e a qualidade dos lucros, além de reduzir os custos de conformidade com a preparação de duas demonstrações - uma para o fisco e outra para o mercado de capitais (Hanlon \& Shevlin, 2005; Desai, 2005; Frank, Lynch, \& Rego, 2009; Blaylock, Gaertner, \& Shevlin, 2015).

Entre outros fatores, essa melhora na qualidade do lucro seria possível, pois, maior conformidade possibilita que as autoridades tributárias atuem como monitores adicionais do lucro divulgado, além permitir que os investidores observem os impostos pagos. Logo, a exigência de maior CFF restringiria o comportamento oportunista dos gestores, melhorando, assim, a qualidade do lucro (Atwood, Drake, \& Myers, 2010).

Mais especificamente, os defensores da CFF argumentam que maior conformidade desestimularia o gerenciamento de resultados e de impostos, à medida que o incentivo por parte dos gestores em enganar para fins financeiros ou fiscais seria reduzido, devido a maior proximidade do lucro tributável com o contábil, e/ou vice-versa (Desai, 2005).

Nesse sentido, Desai (2005) explica que um sistema que possibilita os gestores caracterizarem o lucro conforme o público legitima a manipulação dos resultados. Logo, restringir os gestores a uma definição de lucro pode limitar o impulso de caracterizar os resultados contábil e tributável oportunisticamente, seja pela redução da discricionariedade ou pelo aumento dos custos do oportunismo.

À medida que há maior CFF, a discricionariedade dos gestores seria restringida e, assim, reduzir-se-iam os accruals a serem utilizados no gerenciamento/suavização do lucro contábil sem afetar, com isso, o lucro tributável. Além disso, a elevada CFF resultaria num aumento dos custos do oportunismo, pois o GR para cima seria contrariado por impostos mais elevados, e o gerenciamento para evitar impostos seria desaprovado pelos investidores, à medida que o lucro divulgado a eles seria menor (Blaylock, Gaertner, \& Shevlin, 2015).

Nesse contexto, é possível identificar alguns estudos que encontraram uma relação negativa entre CFF e GR. Por exemplo, Frank, Lynch e Rego (2009) constataram uma associação positiva entre o lucro contábil manipulado para cima e o lucro tributável gerenciado para baixo, consistente com a ideia de que a não conformidade possibilita o gerenciamento de tributos e de resultados. Já Tang (2014), partindo 
de uma amostra de 32 países ao longo de 1995 a 2007, verificou que a maior CFF esteve associada a menores níveis de gerenciamento tributário e de resultados.

Por outro lado, a maior interferência dos legisladores fiscais também é capaz de deteriorar a qualidade dos lucro divulgado aos investidores, por diversas razões (Atwood, Drake \& Myers, 2010). Primeiro, porque as demandas informacionais dos legisladores são diferentes das demandas dos investidores, $\mathrm{e}$ dificilmente aqueles irão satisfazer as necessidades de informação destes (Yoon, 2008).

Segundo, porque a elevada CFF pode fazer com que os gestores se preocupem mais em divulgar lucros menores, a fim de pagar menos impostos. Dessa forma, a contabilidade financeira pode diferir da atividade econômica subjacente, não refletindo o verdadeiro desempenho econômico da empresa (Guenther \& Young, 2000; Ali \& Hwang, 2000). Todos esses fatores fazem com que o conteúdo informacional dos resultados seja reduzido, prejudicando, assim, a relevância das informações contábeis (Hanlon, Maydew, \& Shevlin, 2008).

Para os críticos da CFF, essa perda de informação pode fazer com que a proximidade entre os lucros contábil e tributável estimule a prática de GR nas empresas. Primeiramente, a perda de informação decorrente da maior CFF pode elevar a suavização de resultados, a fim de evitar maiores impostos (Blaylock, Gaertner, \& Shevlin, 2015). Além disso, ao elevar a conformidade, a book-tax differences (BTD) é reduzida, não podendo mais ser utilizada pelos investidores para detectar o gerenciamento, o que pode levar a um aumento da manipulação.

Isso ocorre, pois, a BTD pode ser utilizada como uma proxy para identificar o GR e a agressividade fiscal, uma vez que os gestores têm incentivos para maximizar o lucro contábil e reduzir o lucro tributável (Tang, 2005). Dessa forma, as diferenças tributárias acabam sendo compostas pelas diferenças oportunistas originadas das escolhas gerenciais de divulgação contábil e fiscal, ou seja, pelo GR e pelo gerenciamento de tributos - o que forma a BTD anormal (Tang, 2005; Costa, 2012).

Assim, ao conformar o lucro contábil e o tributável em uma única medida, o mercado de capitais perde conteúdo informacional, especificamente no que tange a BTD. Por conseguinte, a perda dessa informação pode estimular a prática de GR, visto que os investidores não teriam mais como identificar a manipulação por meio dessa proxy (Hanlon, Laplante, \& Shevlin, 2005; Blaylock, Gaertner, \& Shevlin, 2015).

Nesse sentido, existem evidências empíricas condizentes com a maior conformidade elevando o nível de GR. Por exemplo, Burgstahler, Hail e Leuz (2006), ao estudarem países da União Europeia, observaram que a CFF foi positivamente relacionada ao GR. Também, Watrin, Ebert e Thomsen (2014), ao coletarem demonstrações financeiras individuais e consolidadas de empresas europeias de 2004 a 2011, apuraram uma relação positiva entre a conformidade das demonstrações financeiras individuais e fiscais e o GR em demonstrações consolidadas.

Por sua vez, Blaylock, Gaertner e Shevlin (2015) realizaram sua pesquisa em 35 países durante 1996 e 2007, e concluíram que a CFF está relacionada a maior GR. Para os autores, isso ocorre porque quando a conformidade é alta, as empresas suavizam mais os resultados devido às considerações tributárias e ao baixo risco de detecção do gerenciamento.

Em resumo, tanto a literatura quanto as pesquisas empíricas demonstram que o nível de CFF exigido em um país pode elevar ou reduzir o GR. Contudo, o que se verifica é que à medida que há maior CFF, esta é capaz de reduzir o GR pela inibição que a primeira causa no comportamento oportunista do gestor, ainda que possa haver perda de informação ao usuário externo. É o que afirmam Blaylock, Gaertner e Shevlin (2015) ao constatarem que os investidores preferem maiores níveis de CFF, mesmo com a perda informacional, caso essa esteja acompanhada por uma redução suficientemente grande no nível de GR. 
Nessa perspectiva, assume-se que a maior CFF traria maiores benefícios em decorrência da limitação no GR do que custos relacionados à perda de informação. Partindo desse pressuposto, o estudo levanta a seguinte hipótese operacional:

$\mathrm{H}_{1 a}: \mathrm{O}$ grau de conformidade financeira e fiscal exigido nos países impacta negativamente o nível de gerenciamento de resultados.

\subsection{Origem do Sistema Jurídico: Common Law e Code Law}

As leis e sua aplicação variam entre os países e isso se deve, em parte, por conta das diferenças decorrentes da origem legal, que advém de duas tradições mais abrangentes: common law, que possui origem inglesa, e code law, derivada das leis romanas (La Porta, Lopez-de-Silanes, Shleifer, \& Vishny, 1998).

Em nações common law, as leis e sua aplicação são guiadas pelo direito consuetudinário, em que se escreve o mínimo possível e se deixa aos julgadores a aplicação do conteúdo legal com base nos costumes, na tradição e na jurisprudência (Martins, Martins, \& Martins, 2007). Portanto, observa-se que nesse sistema há pouca interferência governamental no estabelecimento das práticas contábeis, sendo essas determinadas primeiramente pelo setor privado (Ball, Kothari, \& Robin, 2000). Sendo assim, as legislações contábil e fiscal se tornam mais independentes, o que contribui para um menor nível de CFF.

Já os países code law são regidos pelo direito romano, cujas leis são um conjunto de requerimentos e procedimentos bem detalhados, sendo as práticas contábeis incorporadas em leis nacionais (Choi \& Meek, 2011). Então, como esses países tendem a ser orientados por regras, o governo acaba apresentando maior interferência sobre a contabilidade (Ball, Kothari, \& Robin, 2000). Isso faz com que os países desse sistema apresentem maior proximidade entre as normas contábeis e fiscais, ou seja, favorece uma CFF mais elevada.

Deve-se destacar, entretanto, que dentro da tradição code law existem três grandes famílias das quais as leis comerciais modernas se originam: a francesa, alemã e escandinávia. As duas primeiras, assim como a tradição common law, espalharam-se pelo mundo através de uma combinação de conquistas, imperialismo, empréstimo e imitação. Apesar disso, as leis dos países componentes de um dos sistemas não são iguais, pois além de refletirem as influências das tradições, também transmitem as revisões específicas e individuais feitas por cada nação ao longo do tempo (La Porta et al., 1998).

Dessa forma, a normatização contábil dos países acaba divergindo entre si, mesmo que esses façam parte de um mesmo sistema legal. Exemplos disso são os EUA e o Reino Unido que, apesar de terem a mesma origem common law, apresentam sistemas de divulgação financeira distintos. No primeiro, a normatização contábil é baseada em regras, visto que os US-GAAP apresentam um guia detalhado de implementação, além de fornecerem exceções ao escopo e tratamento especial a certos itens (Schipper, 2003). Já no Reino Unido, essa normatização é baseada em princípios, prevendo as normas a flexibilidade para o julgamento profissional (Benston, Bromwich, \& Wagenhofer, 2006).

De qualquer forma, é importante considerar que classificação do sistema legal de um país contribui para o nível de CFF exigido, o que pode interferir na sua relação com o GR. Nesse sentido, Tang (2014) apresenta evidências de que o efeito da CFF sobre o gerenciamento é mais pronunciado em países code law. Logo, a segunda hipótese levantada é:

$\mathrm{H}_{1 \mathrm{~b}}$ : A relação entre o gerenciamento de resultados e o nível de conformidade financeira e fiscal é diferente entre os países common e code law. 


\section{PROCEDIMENTOS METODOLÓGICOS}

3.1 Amostra e Coleta de Dados

Para consecução do objetivo, partiu-se de uma amostra de países componentes do Grupo dos Vinte (G-20), onde foram coletadas informações contábeis de empresas não financeiras listadas na principal Bolsa de Valores de cada país, durante o período de 2006 a 2016. Para compor a amostra, exigiu-se que cada país-ano tivesse no mínimo 35 observações utilizáveis (Tang, 2014). Assim, a amostra foi composta por 26 países, conforme apresentado na Tabela 1.

Tabela 1 - Quantidade de empresas por país

\begin{tabular}{|c|c|c|c|c|c|}
\hline País & Sistema legal(1) & Bolsa utilizada & Total & Excluídas & Amostra \\
\hline África do Sul & Common Law & Johannesburg Stock Exchange & 455 & 227 & 228 \\
\hline Alemanha & Code Law & Deutsche Boerse AG & 1.166 & 644 & 522 \\
\hline Argentina & Code Law & Bolsa de Comercio de Buenos Aires & 85 & 20 & 65 \\
\hline Austrália & Common Law & Australian Securities Exchange & 2.256 & 599 & 1.657 \\
\hline Áustria & Code Law & Vienna Stock Exchange & 90 & 35 & 55 \\
\hline Bélgica & Code Law & Euronext.liffe Brussels & 294 & 194 & 100 \\
\hline Brasil & Code Law & B3 - Brasil Bolsa Balcão & 502 & 241 & 261 \\
\hline Canadá & Common Law & Toronto Stock Exchange & 1.961 & 1.333 & 628 \\
\hline China & Code Law & Shanghai Stock Exchange & 1.462 & 236 & 1.226 \\
\hline Coreia do Sul & Code Law & Korea Exchange & 1.254 & 561 & 693 \\
\hline Croácia & Code Law & Zagreb Stock Exchange & 158 & 83 & 75 \\
\hline Espanha & Code Law & Bolsa de Madrid & 243 & 86 & 157 \\
\hline EUA & Common Law & NYSE & 2.536 & 1.159 & 1.377 \\
\hline Finlândia & Code Law & Nasdaq Helsinki & 160 & 39 & 121 \\
\hline França & Code Law & Euronext.liffe Paris & 1.214 & 566 & 648 \\
\hline Grécia & Code Law & Athens Stock Exchange & 218 & 36 & 182 \\
\hline Holanda & Code Law & Euronext.liffe Amsterdam & 144 & 57 & 87 \\
\hline Índia & Common Law & National Stock Exchange of India & 1.955 & 418 & 1.537 \\
\hline Indonésia & Code Law & Indonesia Stock Exchange & 574 & 144 & 430 \\
\hline Itália & Code Law & Bolsa de Valores da Itália & 455 & 228 & 227 \\
\hline Japão & Code Law & Japan Exchange Group & 3.038 & 420 & 2.618 \\
\hline México & Code Law & Bolsa Mexicana de Valores & 198 & 87 & 111 \\
\hline Reino Unido & Common Law & London Stock Exchange & 1.678 & 531 & 1.147 \\
\hline Romênia & Code Law & Bucharest Stock Exchange & 368 & 263 & 105 \\
\hline Rússia & Code Law & MICEX - RTS & 277 & 70 & 207 \\
\hline Turquia & Code Law & Borsa İstanbul & 455 & 187 & 268 \\
\hline Total & & & 23.196 & 8.464 & 14.732 \\
\hline
\end{tabular}

Fonte: Elaboração própria

(1) Classificação baseada no estudo de La Porta et al. (1998)

Os dados apresentados na Tabela 1 foram obtidos na base de dados Thomson Reuters Datastream e se referem às empresas ativas das principais Bolsas de Valores de cada país que divulgaram suas demonstrações contábeis em moeda local. Dessa forma, o estudo partiu de uma população de 23.196 empresas atualmente listadas nos países estudados.

Posteriormente, excluiu-se as empresas do setor financeiro (bancos, empresas de serviços financeiros, fundos de investimento e empresas de seguro) e aquelas com ativo total igual a zero, com lucro líquido antes dos impostos igual ou menor que zero e despesa tributária corrente negativa. As empresas com ativo total nulo foram excluídas, pois é provável que a base de dados tenha apresentado um erro. Por 
sua vez, as exclusões de firmas com lucro igual a zero ou prejuízos e com despesas tributárias nulas ou negativas se justificam pela necessidade do cálculo da BTD, por meio da qual é desenvolvida a medida de CFF dos países.

Após todas as exclusões, a amostra final foi composta por um total de 14.732 empresas listadas em 26 países. Conforme pode ser observado na Tabela 1, a amostra inclui países com diferentes tamanhos e níveis de desenvolvimento do mercado de capitais (Leuz, Nanda, \& Wysocki, 2003). Por exemplo, a Austrália, EUA e Japão possuem mais de 1.000 empresas, enquanto que países como Argentina, Áustria e Croácia possuem menos de 100 firmas listadas.

Por fim, também se observa, com base na classificação de La Porta et al. (1998), que seis países da amostra são de origem common law e vinte são code law. Apesar dessa diferença, ao considerar a quantidade de empresas listadas em cada um desses sistemas, é possível constatar que quase metade das empresas da amostra são de países common law (6.574).

3.2 Modelos

\subsection{1 Índice de Gerenciamento de Resultados}

A fim de analisar o impacto da CFF sobre o GR e considerando que a estrutura fiscal e financeira é determinada a nível-país, o estudo desenvolve uma medida de CFF e um índice de GR para cada nação individualmente e em cada ano em que o país aparece. Para isso, a primeira etapa da pesquisa envolve a estimação dos accruals discricionários necessários para o desenvolvimento dessas medidas. Esses accruals são obtidos a partir do modelo de Kothari, Leone e Wasley (2005) aplicado em cada país, o qual é dado pelo Modelo 1.

$$
\text { TAi,t }=a 0+a 1(1 / A i, t-1)+a 2(\triangle R E C i, t-\Delta C A R i, t)+a 3 I M O B i, t+a 4 R O A i, t-1+\varepsilon i, t
$$

Em que:

$\mathrm{TAi}, \mathrm{t}=$ accruals totais da empresa i no período $\mathrm{t}$, calculado como a variação no ativo circulante não financeiro menos a variação no passivo circulante, excluindo a porção corrente da dívida de longo prazo, menos depreciação e amortização, escalado pelo ativo total em t-1;

Ai,t-1 = ativo total ao final do período $\mathrm{t}-1$;

$\triangle \mathrm{RECi}, \mathrm{t}-\Delta \mathrm{CARi}, \mathrm{t}=$ variação da receita de vendas menos a variação das contas a receber, de $\mathrm{t}-1 \mathrm{at}$, escalado pelo ativo total em $\mathrm{t}-1$;

$\mathrm{IMOBi,t}=$ ativo imobilizado líquido no ano $\mathrm{t}$ dividido pelo ativo total em $\mathrm{t}-1$;

ROAi,t-1 $=$ retorno sobre os ativos em $\mathrm{t}-1$;

$\varepsilon i, t=$ é o erro aleatório da regressão, sendo $\varepsilon i, t \sim N(0, \sigma 2)$.

O estudo optou pelo modelo de Jones (1991) adaptado por Kothari, Leone e Wasley (2005), pois esse se destaca dentre os modelos de GR em virtude da inclusão de uma medida de desempenho, nomeadamente, o ROA (Martinez, 2013).

Para a execução do Modelo 1, utilizou-se dados em painel ajustado por efeitos fixos, uma vez que o estudo foi composto pela população de empresas listadas na principal Bolsa de Valores de cada nação. A partir disso, estimou-se os accruals discricionários, que correspondem aos resíduos da regressão.

Ainda nessa etapa, um índice de GR foi elaborado para cada país em cada ano, o que envolveu quatro passos para seu desenvolvimento. Primeiramente, obteve-se os valores absolutos dos accruals discricionários e, a partir disso, calculou-se sua média para cada país-ano (o que é denominado DACCi). 
Com isso, o intuito foi identificar os países-anos que mais gerenciaram resultados, independentemente dessa manipulação ter sido realizada para aumentar ou reduzir os números contábeis. Logo, um maior DACCi indica maior GR, seja para baixo ou para cima.

Em segundo lugar, os DACCi foram ranqueados por país-ano em ordem ascendente, isto é, em cada ano foi feito um ranking que ordena os países do menor para o maior DACCi. No terceiro passo, foi atribuída uma numeração a essa classificação, que vai de zero (para o país com menor DACCi em um dado ano) a n-1 (para o país com maior DACCi, em que n é a quantidade de países incluídos no ano). Por último, esse ranking foi dividido por n-1, o que resultou num índice de GR que varia de 0 (país com menor nível de gerenciamento) a 1 (país com maior gerenciamento de resultados).

Em suma, o esquema de construção do índice de GR pode ser resumido conforme demonstrado na Figura 1 abaixo.

Figura 1: Esquema de desenvolvimento do índice de $G R$

\begin{tabular}{|c|c|c|c|}
\hline $\begin{array}{c}\text { Accruals discricionários } \\
\text { (DACC) dos países- } \\
\text { anos }\end{array}$ & $\begin{array}{l}\text { Ranqueamento dos } \\
\text { países com maior GR }\end{array}$ & $\begin{array}{l}\text { Enumeração do } \\
\text { ranking }\end{array}$ & Índice de GR \\
\hline $\begin{array}{l}\text { Estimação dos } \\
\text { DACC das } \\
\text { empresas de cada } \\
\text { nação em cada ano. }\end{array}$ & $\begin{array}{l}\text { Para cada ano foi } \\
\text { feita uma } \\
\text { classificação } \\
\text { ascendente das }\end{array}$ & $\begin{array}{l}\text { A tribui-se uma } \\
\text { enumeração a } \\
\text { classificação } \\
\text { alcançada no passo }\end{array}$ & $\begin{array}{l}\text { Divisão da } \\
\text { enumeração do } \\
\text { ranking anterior por } \\
n-1 \text {, de modo a }\end{array}$ \\
\hline $\begin{array}{l}\text { Obtenção dos } \\
\text { valores absolutos } \\
\text { dos DACC. }\end{array}$ & $\begin{array}{l}\text { citadas } \\
\text { anteriormente. }\end{array}$ & $\begin{array}{l}\text { o pais com menor } \\
\text { média de DACC } \\
\text { absolutos e } n-1 \text { a } \\
\text { nação com maior }\end{array}$ & $\begin{array}{l}\text { Indice que varla de o } \\
\text { (país com menor } \\
\text { GR) a } 1 \text { (nação com } \\
\text { maior GR). }\end{array}$ \\
\hline $\begin{array}{l}\text { Cálculo da média } \\
\text { dos valores } \\
\text { absolutos dos DACC } \\
\text { em cada país-ano. }\end{array}$ & & absolutos. & \\
\hline
\end{tabular}

Contudo, deve-se destacar que esse índice de GR pode ser influenciado pela falta de controle dos aproveitamentos legais. Especificamente, a não inclusão de uma variável de controle sobre os incentivos fiscais resultaria em resíduos mais elevados (que correspondem aos accruals discricionários). Assim, o índice de GR, além de refletir a manipulação, poderia estar captando uma parte proveniente de incentivos fiscais.

\subsubsection{Medida de Conformidade Financeira e Fiscal}

O nível de CFF de um país pode variar ao longo dos anos. Levando isso em consideração, a segunda etapa do estudo desenvolve uma medida de CFF a partir da aplicação do Modelo de Tang (2014) em cada país-ano. Assim, as regressões foram realizadas com dados em corte transversal, seguindo o Modelo 2, a seguir.

$$
B T D i, t=\theta 0+\theta 1 D A C C i, t+\theta 2 T P i, t+\theta 3 D A C C * T P i, t+\varepsilon i, t
$$

Em que:

BTDi,t = book-tax differences total da empresa i no ano $t$, que é igual ao lucro contábil antes do imposto de renda (LAIR) multiplicado pela taxa de imposto estatutária (TIE) menos as despesas tributárias correntes (DTC), sendo o resultado escalado pelo ativo total (A);

DACCi, $\mathrm{t}=$ accruals discricionários obtidos a partir dos resíduos do Modelo 1; 
TPi,t = medida de elisão fiscal, calculada como a TIE menos a taxa de imposto efetiva atual (ETR), que é a razão entre a DTC e o LAIR;

DACC*TPi,t = termo de interação entre os accruals discricionários e a medida de elisão fiscal;

$\varepsilon i, t=$ é o erro aleatório da regressão, sendo $\varepsilon i, t \sim N(0, \sigma 2)$.

O Modelo 2 desenvolvido por Tang (2014) utiliza a BTD como variável dependente, a qual é tida como um indicador de agressividade fiscal e de GR pela literatura. Isso ocorre, pois, as manipulações do lucro contábil e do lucro tributável aumentam as diferenças entre eles, ou seja, elevam a BTD (denominada de BTD anormal). Contudo, a BTD também pode ser originada pelas diferenças legítimas existentes entre os padrões contábeis e as regras tributárias (que corresponde à BTD normal) (Tang, 2014).

Com base nisso, o Modelo 2 utiliza a BTD anormal (gerenciamento tributário e gerenciamento de resultados) para explicar as diferenças tributárias. Logo, a parcela que não pode ser explicada pela regressão (REQM) corresponde à BTD normal, ou seja, às diferenças tributárias relacionadas às normas, indicando o nível de CFF mandatória. Portanto, uma maior (menor) REQM indica menor (maior) conformidade.

Contudo, deve-se destacar que a variável REQM pode não conseguir refletir totalmente a parcela de conformidade mandatória. Isso ocorre, pois, a existência de incentivos fiscais é capaz de descontar a despesa tributária a ser paga, o que reduz a ETR e, por conseguinte, aumenta sua diferença em relação a TIE (o que eleva a variável TP). Dessa forma, a variável TP, além de refletir a elisão fiscal, estaria capturando uma parte do aproveitamento proveniente dos incentivos fiscais, o que tiraria uma parcela da conformidade mandatória medida pela REQM.

A partir da REQM de cada país-ano obtida por meio das regressões em corte transversal, é possível, então, construir uma medida de CFF que varie entre países e nos países ao longo dos anos. Para isso, foram seguidos três passos, semelhantemente a etapa anterior. Em primeiro lugar, foi feita uma classificação em ordem decrescente das REQMs, dentro de cada ano, a fim de classificar os países do menor para o maior nível de CFF, dado que maiores REQMs (BTD normal) indicam menor CFF.

Posteriormente, aferiu-se uma numeração a essas nações conforme a classificação obtida em cada ano, variando de 0 a n-1. Então, foi atribuído valor zero ao país com maior REQM em um dado ano, de modo a indicar que esse apresentou o menor nível de conformidade entre as normas contábeis e fiscais em tal ano. Já para o país de menor REQM, atribuiu-se n-1 (onde n é o número de países incluídos naquele ano), denotando que tal foi o país de maior CFF. Por fim, os rankings foram divididos por n-1, de modo a construir uma medida contínua de CFF que variasse de 0 (país com menor CFF) a 1 (nação com maior CFF).

A Figura 2, a seguir, apresenta um resumo do passo a passo da elaboração da medida de CFF.

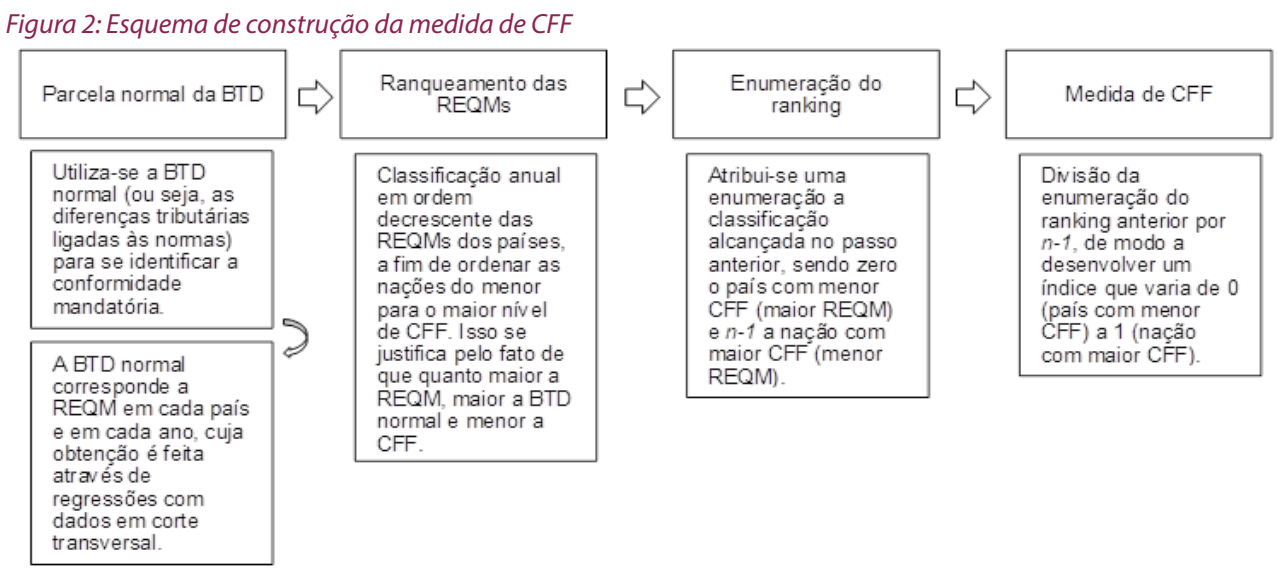

Fonte: Elaboração própria 
Em resumo, o índice de CFF desenvolvido é uma medida relativa entre os países-anos que se baseia nas fontes regulatórias da BTD. Dessa forma, a variável CFF representa o ranking dos países-anos com maior proximidade entre as normas contábeis e fiscais.

\subsubsection{Modelo de Associação entre CFF e GR}

Para examinar a associação entre o nível de CFF e GR, realizou-se uma análise no nível-país, visto que a conformidade mandatória varia entre países, mas não entre empresas. Assim, aplicou-se o Modelo 3 com dados em painel:

GRi,t $=a 0+a 1$ CFFi,t+a2 SLi,t $+a 3$ SL*CFFi,t $+a 4$ PDli,t+a5 ILEGi,t+a6 DMCi,t+a7 DMC*CFFi,t+a8IFRSi,t $+a 91 F R{ }^{*} C F F i, t+\varepsilon i, t$

Onde:

GRi,t = índice de gerenciamento de resultados de cada país i em t;

$\mathrm{CFFi}, \mathrm{t}=$ medida de conformidade financeira e fiscal de um país i no ano $\mathrm{t}$;

$S L i, t=$ dummy que reflete o sistema legal do país, assumindo 0 se common law e 1 se code law;

$S L{ }^{*} \mathrm{CFFi}, \mathrm{t}=$ termo de interação entre o sistema legal e o nível de conformidade;

PDli,t = nível de proteção ao investidor de um país i no ano t, obtido por meio do índice Protecting Minority Investors disponibilizado pelo Banco Mundial (varia de 0 a 10);

ILEGi,t = nível de imposição legal de um país i no ano t, representado pelo índice rule of law do Banco Mundial (em uma escala de $-2,5$ a 2,5);

$\mathrm{DMCi}, \mathrm{t}=$ variável dummy que assume 1 se o mercado de capitais de um país for considerado desenvolvido pela Modern Index Strategy Indexes (MSCl), e 0 caso contrário;

$\mathrm{DMC}{ }^{*} \mathrm{CFFi}, \mathrm{t}=$ termo de interação entre o desenvolvimento do mercado de capitais de um país e seu nível de CFF;

IFRSi,t = variável igual a 1, caso o país i obrigue a adoção das IFRS no ano t, e 0 caso contrário;

IFRS ${ }^{*}$ CFFi,t = termo de interação entre a adoção das IFRS e o nível de CFF;

$\varepsilon i, t=$ é o erro aleatório da regressão, sendo $\varepsilon i, t \sim N(0, \sigma 2)$.

As variáveis de interesse da pesquisa são o nível de CFF e o termo de interação entre o sistema legal e a CFF (SL ${ }^{*} \mathrm{CFF}$ ), sendo que a primeira testa a hipótese H1a e a segunda a hipótese H1b.

Como variáveis de controle, optou-se por algumas características institucionais capazes de influenciar o GR nos países: índice de proteção ao investidor, nível de imposição legal, desenvolvimento do mercado de capitais e adoção das IFRS (Leuz, Nanda, \& Wysocki, 2003; Burgstahler, Hail, \& Leuz, 2006; Barth, Landsman, \& Lang, 2008).

Além de impactar a prática de GR, esses fatores institucionais também são correlacionados com o nível de CFF exigido em uma nação (Blaylock, Gaertner, \& Shevlin, 2015). Assim, o Modelo 3 apresenta alguns fatores de interação entre CFF e (i) sistema legal, (ii) desenvolvimento do mercado de capitais e (iii) adoção das IFRS, pois o efeito da CFF sobre o GR pode variar dependendo dessas características. Portanto, por meio dos termos de interação, o objetivo é saber se e como duas variáveis interagem para explicar a variação no GR (Afshartous \& Preston, 2011). Por fim, o Quadro 1 apresenta uma síntese dos sinais esperados das variáveis do Modelo 3. 
Quadro 1: Sinal esperado das variáveis do Modelo 3

\begin{tabular}{|c|c|l|}
\hline Variável & Sinal esperado & \multicolumn{1}{|c|}{ Explicação } \\
\hline CFF & $(-)$ & $\begin{array}{l}\text { Maior nível de CFF reduz GR, mesmo que haja uma perda de informação (Desai, 2005; Blaylock, } \\
\text { Gaertner, \& Shevlin, 2015). }\end{array}$ \\
\hline SL & $(-)$ & $\begin{array}{l}\text { Países code law (common law) são associados a menor (maior) GR, pois a normatização baseada } \\
\text { em regras (princípios) reduz (aumenta) a discricionariedade dos gestores (Niyama, Rodrigues, \& } \\
\text { Rodrigues, 2015). }\end{array}$ \\
\hline SL*CFF & $(-)$ & $\begin{array}{l}\text { Efeito da CFF sobre o GR é diferente entre os sistemas legais, sendo que em países code law a maior } \\
\text { conformidade reduz o gerenciamento, devido a maior proximidade entre as normas e o próprio } \\
\text { sistema (Tang, 2014; Blaylock, Gaertner, \& Shevlin, 2015). }\end{array}$ \\
\hline PDI & $(-)$ & Forte proteção ao investidor limita os incentivos para GR (Leuz, Nanda, \& Wysocki, 2003). \\
\hline ILEG & $(-)$ & $\begin{array}{l}\text { Forte imposição legal reduz GR, visto o escrutínio regulatório (Leuz, Nanda, \& Wysocki, 2003; } \\
\text { Burgstahler, Hail, \& Leuz, 2006). }\end{array}$ \\
\hline DMC & $(-)$ & $\begin{array}{l}\text { Mercado de capitais desenvolvido reduz assimetria de informação e, consequentemente, a } \\
\text { possibilidade de GR (Leuz, Nanda, \& Wysocki, 2003; Burgstahler, Hail, \& Leuz, 2006). }\end{array}$ \\
\hline DMC*CFF & $(-)$ & $\begin{array}{l}\text { Em países com mercado de capitais desenvolvido, a maior conformidade limita o GR, visto o efeito } \\
\text { do desenvolvimento do mercado e da proximidade das normas sobre o gerenciamento (Blaylock, } \\
\text { Gaertner, \& Shevlin, 2015; Burgstahler, Hail, \& Leuz, 2006). }\end{array}$ \\
\hline IFRS & $(+)$ & $\begin{array}{l}\text { Adoção das IFRS pode aumentar o GR, devido a normatização baseada em princípios e a maior } \\
\text { discricionariedade possibilitada (Ahmed, Neel, \&Wang, 2013; Niyama, Rodrigues, \& Rodrigues, 2015). }\end{array}$ \\
\hline IFRS*CFF & $(+)(-)$ & $\begin{array}{l}\text { O nível de CFF em países que adotam as IFRS pode aumentar (sinal positivo) o GR em virtude das } \\
\text { normas baseadas em princípios, ou reduzir (sinal negativo), em decorrência da maior conformidade } \\
\text { (Niyama, Rodrigues, \& Rodrigues, 2015; Blaylock, Gaertner, \& Shevlin, 2015). }\end{array}$ \\
\hline
\end{tabular}

Fonte: Elaboração própria

\subsection{Análise dos Pressupostos da Regressão}

Em primeiro lugar, para tratar possíveis efeitos de outliers, realizou-se a winsorização dos dados em $1 \%$ e $99 \%$. Além disso, para os modelos que utilizam dados em painel (Modelos 1 e 3), verificou-se a estacionariedade da série por meio do teste de Fisher-Type. Por fim, com relação aos pressupostos da regressão, foram realizados os seguintes tratamentos estatísticos:

a) Heterocedasticidade e autocorrelação: a fim de obter erros-padrão consistentes com possíveis problemas de heterocedasticidade e autocorrelação, os Modelos 1 e 2 foram executados com erros-padrão robustos clusterizados por indústria. Já no Modelo 3, a existência dessas violações foi verificada mediante os testes de Wald e Wooldridge, respectivamente.

b) Multicolinearidade: com o intuito de verificar se as variáveis explicativas de cada modelo são fortemente correlacionadas, procedeu-se a estatística Fator de Inflação da Variância (FIV). Nesse caso, se o FIV for maior que dez, constata-se a multicolinearidade. Porém, destaca-se que nos modelos 2 e 3, que incluem termo de interação, é provável que haja problemas de multicolinearidade em virtude da inclusão de duas variáveis aditivas e seu produto. Considerando isso, utilizou-se a técnica de centralização das variáveis (no Modelo 3), que consiste em subtrair cada valor observado de uma variável contínua por sua média para, posteriormente, calcular a interação. Assim, espera-se reduzir esse problema (Afshartous \& Preston, 2011). Contudo, no caso do Modelo 2, a multicolinearidade não representa um problema, visto que seu objetivo é a previsão da REQM (Gujarati \& Porter, 2011).

d) Normalidade dos resíduos: para testar se os resíduos dos modelos possuem distribuição aproximadamente normal foi realizado o teste de Shapiro-Wilk. No caso em que o valor-p rejeita a hipótese nula de normalidade, entretanto, pode-se apelar ao Teorema do Limite Central, segundo o qual as estatísticas de teste seguirão assintoticamente as distribuições apropriadas (Brooks, 2014).

\section{ANÁLISE DOS RESULTADOS}

4.1 Ranking dos Países 
Com relação ao Modelo 1 de GR, foi observada a ausência de multicolinearidade entre as variáveis e a estacionariedade das séries em todos os países analisados. Apesar disso, esse modelo não apresentou significância estatística na Áustria, Croácia, México e Romênia. Logo, optou-se por excluir esses países da análise, a fim de manter uma maior robustez nos resultados.

Posteriormente, obteve-se os accruals discricionários e se desenvolveu o índice de GR dos países-anos. Para fins de discussão, a Tabela 2 apresenta o ranking desse índice para o período, o qual é calculado a partir da média dos índices de cada país durante os anos.

Tabela 2: Ranking de países com maior índice de gerenciamento de resultados do período

\begin{tabular}{|c|c|c|c|c|}
\hline \multicolumn{5}{|c|}{ Painel A: Ranking dos países com maior índice médio de gerenciamento } \\
\hline Rank & País & Sistema legal & Índice médio de GR & Média DACC \\
\hline $1^{\circ}$ & Espanha & Code law & 0,9221 & 0,05576 \\
\hline $2^{\circ}$ & Holanda & Code law & 0,9047 & 0,05222 \\
\hline $3^{\circ}$ & Canadá & Common law & 0,8745 & 0,05035 \\
\hline $4^{\circ}$ & Bélgica & Code law & 0,8615 & 0,05197 \\
\hline $5^{\circ}$ & Austrália & Common law & 0,8398 & 0,04877 \\
\hline $6^{\circ}$ & Finlândia & Code law & 0,7792 & 0,04880 \\
\hline $7^{\circ}$ & Itália & Code law & 0,6753 & 0,04543 \\
\hline $8^{\circ}$ & Reino Unido & Common law & 0,6753 & 0,04463 \\
\hline $9^{\circ}$ & EUA & Common law & 0,5931 & 0,04311 \\
\hline $10^{\circ}$ & Grécia & Code law & 0,5844 & 0,04228 \\
\hline $11^{\circ}$ & Alemanha & Code law & 0,5628 & 0,04210 \\
\hline $12^{\circ}$ & França & Code law & 0,4978 & 0,04090 \\
\hline $13^{\circ}$ & Índia & Common law & 0,4978 & 0,03824 \\
\hline $14^{\circ}$ & Rússia & Code law & 0,3723 & 0,03583 \\
\hline $15^{\circ}$ & Argentina & Code law & 0,2554 & 0,03016 \\
\hline $16^{\circ}$ & Japão & Code law & 0,2467 & 0,02966 \\
\hline $17^{\circ}$ & Brasil & Code law & 0,2338 & 0,03010 \\
\hline $18^{\circ}$ & Coreia do Sul & Code law & 0,1948 & 0,02804 \\
\hline $19^{\circ}$ & Indonésia & Code law & 0,1775 & 0,02762 \\
\hline $20^{\circ}$ & Turquia & Code law & 0,1212 & 0,02636 \\
\hline $21^{\circ}$ & África do Sul & Common law & 0,1212 & 0,02616 \\
\hline $22^{\circ}$ & China & Code law & 0,0087 & 0,02160 \\
\hline Painel B: Comparação do índice de gerenciamento de resultados entre países common e code law \\
\hline & & Common Law & Code Law & Estatistica Z \\
\hline Média $^{\circ}$ & 0,6003 & 0,4624 & $3,151^{* * * *}$ \\
\hline
\end{tabular}

Fonte: Resultados da pesquisa

Primeiro, deve-se destacar que o índice médio de GR do Painel A da Tabela 2 denota a classificação média de cada país durante o período. Por exemplo, a Espanha apresentou um índice de 0,9221, o que significa que esse país atingiu, na maioria dos anos, as primeiras posições dentre os países analisados. Logo, pode-se afirmar que esse foi o país com maior índice de gerenciamento no período, seguido pela Holanda e pelo Canadá (sendo os dois primeiros países do sistema code law).

De maneira inversa, a China (code law) foi o país que ocupou, em média, posições mais baixas nos anos observados, sendo a nação com menor índice de GR no período. Adicionalmente, foi verificado que a África do Sul (common law) e a Turquia (code law) também foram os países que menos gerenciaram resultados. 
A última colocação da China pode ser explicada por Chen, Lee e Li (2008), que argumentam que o GR por meio de accruals são mais raros nesse país, e que o principal meio de gerenciamento são as transações reais que envolvem ganhos não operacionais e/ou itens abaixo da linha. Ainda, esse resultado pode estar ligado ao sistema legal do país, que resulta em normas de contabilidade baseadas em regras.

Similarmente, o Brasil, que também é caracterizado como de origem code law, deteve uma classificação de relativo baixo nível de GR (17\%). Especificamente, pode ser observado que o país ocupou a $6^{a}$ posição dentre os países que menos gerenciaram resultados no período, o que pode estar relacionado a origem legal.

Com efeito, o Painel B da Tabela 2 demonstra que países code law detêm menor índice de gerenciamento $(0,4624)$ do que países common law $(0,6003)$, e que essa diferença é significante. Esse resultado é consistente com Niyama, Rodrigues e Rodrigues (2015), que argumentam que a flexibilidade das normas nos países common law pode aumentar a utilização de mecanismos de GR, visto que as regras são baseadas em princípios.

O estudo também apresenta, na Tabela 3, o ranking de conformidade financeira e fiscal mandatória dos países para o período, o qual é calculado como sendo a média de CFF de cada nação durante os anos, cuja obtenção é descrita na seção 3.2.2.

Tabela 3: Ranking dos países com maior nível de CFF no período

\begin{tabular}{|c|c|c|c|c|}
\hline \multicolumn{5}{|c|}{ Painel A: Ranking dos países com maior CFF } \\
\hline Rank & País & Sistema legal & CFF média & Média REQM \\
\hline $1^{\circ}$ & Coreia do Sul & Code law & 0,8987 & 0,00527 \\
\hline $2^{\circ}$ & Finlândia & Code law & 0,8954 & 0,00509 \\
\hline $3^{\circ}$ & China & Code law & 0,8467 & 0,00562 \\
\hline $4^{\circ}$ & Japão & Code law & 0,8203 & 0,00574 \\
\hline $5^{\circ}$ & Grécia & Code law & 0,7167 & 0,00644 \\
\hline $6^{\circ}$ & Holanda & Code law & 0,7015 & 0,00675 \\
\hline 70 & Espanha & Code law & 0,6342 & 0,00749 \\
\hline $8^{\circ}$ & Itália & Code law & 0,6307 & 0,00734 \\
\hline $9^{\circ}$ & Argentina & Code law & 0,6054 & 0,00837 \\
\hline $10^{\circ}$ & Indonésia & Code law & 0,5931 & 0,00764 \\
\hline $11^{\circ}$ & Rússia & Code law & 0,5011 & 0,00867 \\
\hline $12^{\circ}$ & África do Sul & Common law & 0,4859 & 0,00921 \\
\hline $13^{\circ}$ & França & Code law & 0,4781 & 0,00853 \\
\hline $14^{\circ}$ & Turquia & Code law & 0,4206 & 0,00952 \\
\hline $15^{\circ}$ & Índia & Common law & 0,3768 & 0,00989 \\
\hline $16^{\circ}$ & Brasil & Code law & 0,3374 & 0,01061 \\
\hline $17^{\circ}$ & Alemanha & Code law & 0,2887 & 0,01086 \\
\hline $18^{\circ}$ & Bélgica & Code law & 0,2843 & 0,01150 \\
\hline $19^{\circ}$ & Reino Unido & Common law & 0,2768 & 0,01095 \\
\hline $20^{\circ}$ & Canadá & Common law & 0,1052 & 0,01522 \\
\hline $21^{\circ}$ & EUA & Common law & 0,0567 & 0,01964 \\
\hline \multicolumn{5}{|c|}{ Painel B: Comparação da medida de CFF entre países common e code law } \\
\hline & \multicolumn{2}{|c|}{ Common Law } & Code Law & Estatística Z \\
\hline Média & \multicolumn{2}{|c|}{0,2203} & 0,6045 & $-8,724 * * *$ \\
\hline
\end{tabular}

Fonte: Resultados da pesquisa

Como pode ser constatado no Painel A da Tabela 3, os países que tiveram maior nível de CFF no período foram a Coréia do Sul, Finlândia e China, que são países de origem code law. Por outro lado, os 
países com menor nível de conformidade foram a Austrália, EUA e Canadá, que são países classificados como common law.

Nesse contexto, Ali e Hwang (2000) explicam que, geralmente, os países de baixa CFF são do grupo Americano-Britânico, tais como EUA, Austrália, Canadá e Reino Unido. De fato, esses foram os países que detiveram menor nível de conformidade mandatória, ocupando quatro das cinco posições de menor CFF.

Aliás, é possível observar que as onze primeiras posições foram dominadas por países de origem code law, enquanto que as últimas colocações foram ocupadas por países common law. Logo, esses resultados são consistentes com a teoria e achados de pesquisas anteriores de que em países code law a CFF é maior (Ball, Kothari, \& Robin, 2000; Tang, 2014).

Deveras, o Painel B da Tabela 3 corrobora essa análise, à medida que demonstra que a média de CFF foi significativamente maior em países de origem code law $(0,6045)$ do que em nações common law $(0,2203)$. Para Ball, Kothari e Robin (2000) e Choi e Meek (2011), a maior CFF em países do sistema code law pode ser explicada pela forte interferência governamental e pela influência da regulação e da contabilidade fiscal sobre as demonstrações.

Por último, destaca-se que o ranking obtido no estudo se assemelha, em alguns pontos, com a classificação de Atwood, Drake e Myers (2010) - cuja pesquisa buscou examinar se o nível de CFF afeta a persistência dos resultados e sua associação com os fluxos de caixa futuros. Ao analisar a medida de CFF (REQM) obtida pelos autores, é possível notar que em seus resultados os EUA e o Canadá também estiveram entre os países com menor CFF, enquanto que a China, Coreia do Sul e Japão também compuseram os cinco países de maior CFF.

Finalmente, com relação ao Brasil, foi verificado que o país obteve a 16a colocação entre os países com maior CFF do período, o que é uma posição de relativa baixa conformidade. Esse resultado pode surpreender, uma vez que o Brasil é tipificado por ter forte interferência governamental no estabelecimento de normas e práticas contábeis, e sua legislação fiscal influenciava os procedimentos contábeis (Niyama, Costa, \& Aquino, 2005).

Contudo, os resultados obtidos podem representar a mudança nesse cenário em virtude da convergência às IFRS, que promoveu uma desvinculação entre o Fisco e a Contabilidade e resultou num aumento das diferenças tributárias, isto é, reduziu o nível de CFF (Costa, 2012).

\subsection{Impacto da Conformidade Financeira e Fiscal sobre o Gerenciamento de Resulta-}

dos

Para responder à questão levantada, utilizou-se o Modelo 3. Primeiramente, deve-se destacar que, por meio do teste de Fisher-Type, foi constatado que a maioria das variáveis eram estacionárias, com exceção da variável PDI, que apresentou raiz unitária. Logo, essa foi utilizada em primeira diferença.

Com relação à multicolinearidade, aplicou-se a técnica de centralização das variáveis na média, a fim de reduzir esse problema. Entretanto, essa técnica ajuda a melhorar problemas de multicolinearidade decorrentes do dimensionamento das variáveis, isto é, de multicolinearidade não essencial. Por outro lado, a centralização não é capaz de reduzir a multicolinearidade essencial, que surge devido à relação/ inclinação entre as variáveis independentes (Afshartous \& Preston, 2011).

Nesse sentido, a partir do cálculo do FIV, foi verificado que a variável CFF apresentava indícios de forte multicolinearidade ( $F I V=14,30$ ), e que o fator de interação $S L{ }^{*}$ CFF contribuiu para isso ( $F I V=6,81$ ). Sendo assim, pode-se afirmar que há multicolinearidade essencial entre as variáveis CFF e SL, uma vez que a centralização não conseguiu reduzir essa relação. 
Com efeito, a literatura e os resultados do Painel B da Tabela 3 demonstram que o nível de CFF e a origem legal são correlacionados, e que países code law apresentam maior CFF (Ball, Kothari, \& Robin, 2000; Blaylock, Gaertner, \& Shevlin, 2015). Portanto, optou-se por relaxar o pressuposto da multicolinearidade, visto que os estimadores ainda conservarão a propriedade de Melhores Estimadores Lineares Não Viesados (Gujarati \& Porter, 2011).

Quanto aos problemas de heterocedasticidade e autocorrelação, os testes de Wald e Wooldrige apontaram a existência dessas violações. Desse modo, aplicou-se a clusterização nos países, a fim de obter erros-padrão robustos mesmo na presença de heterocedasticidade e autocorrelação.

Também, realizou-se o teste de normalidade dos resíduos de Shapiro-Wilk, o que indicou que os erros não seguiam uma distribuição normal. Contudo, com base no Teorema do Limite Central, pode-se relaxar esse pressuposto, pois as estatísticas seguirão assintoticamente as distribuições apropriadas, mesmo na ausência de normalidade dos erros (Brooks, 2014).

Por fim, como o Modelo 3 utiliza dados em painel, também foram realizados testes para constatar qual modelo era mais adequado: efeitos fixos, aleatórios ou pooled. Nesse sentido, o teste de Chow indicou o modelo de efeitos fixos em detrimento do pooled, enquanto que o teste de Breush-Pagan rejeitou o modelo pooled em prol do de efeitos aleatórios. Enfim, o teste de Hausman revelou que o modelo mais adequado era o de efeitos aleatórios e não o de efeitos fixos. Finalmente, a Tabela 4 apresenta os resultados obtidos para o Modelo 3.

Tabela 4: Resultados do Modelo 3

\begin{tabular}{|c|c|c|c|}
\hline Variáveis & Sinal esperado & Coeficiente & Valor-p \\
\hline CFF & $(-)$ & $-0,1674^{* *}$ & 0,047 \\
\hline SL & $(-)$ & $-0,0143$ & 0,851 \\
\hline $\mathrm{SL}^{*} \mathrm{CFF}$ & $(-)$ & 0,0169 & 0,800 \\
\hline PDI & $(-)$ & $-0,0009$ & 0,963 \\
\hline ILEG & $(-)$ & $-0,0347$ & 0,526 \\
\hline DMC & $(-)$ & $0,4813^{* * *}$ & 0,000 \\
\hline $\mathrm{DMC}^{*} \mathrm{CFF}$ & $(-)$ & $-0,0512$ & 0,503 \\
\hline IFRS & $(+)$ & 0,0167 & 0,652 \\
\hline IFRS*CFF & $(+)(-)$ & $0,1725^{* *}$ & 0,024 \\
\hline Constante & $?$ & $0,2320^{* *}$ & 0,017 \\
\hline \multicolumn{2}{|l|}{ Obs. } & \multicolumn{2}{|c|}{218} \\
\hline \multicolumn{2}{|l|}{$\mathrm{R} 2$} & \multicolumn{2}{|c|}{0,5787} \\
\hline \multicolumn{2}{|l|}{ F/Wald chi2 } & \multicolumn{2}{|c|}{$62,81^{* * *}$} \\
\hline \multicolumn{2}{|c|}{ Shapiro-Wilk(valor-p) } & \multicolumn{2}{|c|}{$0,0000^{* * *}$} \\
\hline \multicolumn{2}{|c|}{ Teste de Hausman (valor-p) } & \multicolumn{2}{|c|}{0,5722} \\
\hline \multicolumn{2}{|c|}{ Teste de Breush-Pagan (valor-p) } & \multicolumn{2}{|c|}{$0,0000^{* * *}$} \\
\hline \multicolumn{2}{|c|}{ Teste de Chow (valor-p) } & \multicolumn{2}{|c|}{$0,0000^{* * *}$} \\
\hline
\end{tabular}

Como pode ser verificado na Tabela 4, o modelo proposto foi estatisticamente significante a 1\%, explicando 57,87\% da variação do índice de GR. Além disso, é possível constatar que o GR apresentou associação significante com o nível de conformidade financeira e fiscal (CFFi), desenvolvimento do mercado de capitais (DMC) e com a interação entre a adoção das IFRS e o nível de conformidade (IFRS*CFF).

Conforme observado, o nível de CFF apresentou uma associação negativa e significante com o GR, ao nível de 5\% de significância. Logo, é possível corroborar a hipótese H1a de que o grau de conformidade 
financeira e fiscal exigido nos países impacta negativamente o nível de gerenciamento de resultados. Desse modo, pode-se afirmar que um aumento no nível de conformidade financeira e fiscal dos países está associado a uma redução na prática de GR, indo ao encontro dos resultados de Frank, Lynch e Rego (2009) e Tang (2014).

Teoricamente, esse resultado é consistente com a hipótese de que a maior CFF reduz a discricionariedade e a possibilidade de os gestores gerenciarem resultados, visto que a proximidade entre os lucros contábil e tributável reduziriam os incentivos por parte dos executivos de manipular os resultados: ao gerenciar o lucro contábil para cima, as empresas teriam sua carga tributária elevada, e ao gerenciar o lucro tributável para baixo, o resultado divulgado para os investidores seria menor, o que também é indesejado (Desai, 2005; Hanlon \& Shevlin, 2005; Blaylock, Gaertner \& Shevlin, 2015).

Não obstante, o gerenciamento de resultados apresentou uma associação positiva com o desenvolvimento do mercado de capitais, indicando que, nos países pesquisados, os mercados desenvolvidos estão relacionados a um índice maior de gerenciamento de resultados.

Esse resultado é diferente do esperado, pois a maioria dos estudos aponta que o gerenciamento de resultados é menor em países com mercado de capitais avançado (Leuz, Nanda, \& Wysocki, 2003; Burgstahler, Hail, \& Leuz, 2006). Apesar disso, as empresas situadas nesses países podem ter incentivos diferentes para gerenciar resultados, como o próprio mercado (Burgstahler, Hail, \& Leuz, 2006).

Por exemplo, o papel exercido pelos analistas seria maior em mercados desenvolvidos, gerando maior pressão sobre as empresas para atingir certos resultados e, consequentemente, maiores incentivos ao GR. Também, em países com mercado de capitais desenvolvido, os gestores estariam mais propensos a gerenciar resultados para evitar resultados negativos, a fim de atender as expectativas dos investidores (Brown \& Higgins, 2005).

Finalmente, também foi constatada uma associação positiva entre o termo de interação IFRS*CFF e o gerenciamento de resultados. Esse resultado indica que o efeito da CFF sobre o GR é diferente entre os países-anos que realizaram ou não a convergência com as IFRS. Aliás, pode-se afirmar que em países e períodos de adoção das IFRS, a elevada CFF está relacionada a maior gerenciamento de resultados do que em países-anos que ainda não realizaram a convergência ou que não adotaram as normas internacionais.

Uma possível explicação para esse resultado está relacionada à relevância das informações contábeis (value relevance), especificamente da BTD. Como exposto anteriormente, a perda de informação da BTD, que é considerada uma proxy do GR, pode levar à uma relação positiva entre CFF e GR, pois os investidores teriam reduzida a sua capacidade de identificar a manipulação de resultados (Blaylock, Gaertner, \& Shevlin, 2015).

Não obstante, a adoção das IFRS geralmente está associada a um aumento na relevância das informações contábeis (Barth, Landsman, \& Lang, 2008). Nesse contexto, a BTD seria uma informação mais relevante e apresentaria maior montante, uma vez que a adoção das IFRS promove um distanciamento entre as normas contábeis e tributárias (Costa, 2012). Portanto, aumentar o nível de CFF em países que realizaram a convergência reduziria o montante da BTD e sua relevância, o que resultaria num aumento do nível de GR, devido à perda informacional (Guenther \& Young, 2000; Ali \& Hwang, 2000).

Por fim, foi constatado que o efeito da conformidade financeira e fiscal sobre o gerenciamento de resultados não divergiu entre países do sistema common law ou code law (SL*CFF), o que é diferente do resultado obtido por Tang (2014). Dessa maneira, não foi possível corroborar a hipótese H1b de que a relação entre o gerenciamento de resultados e o nível de conformidade financeira e fiscal é diferente entre os países common e code law. 
Esse resultado pode ocorrer em virtude do reflexo causado pelas diferenças oriundas das tradições de cada país e a aplicação legal realizada por cada um ao longo do tempo (La Porta et al., 1998). Ainda há que se levar em consideração ao cenário ora analisado que a origem legal se distancia da prática contábil à medida que os países de origem code law passam a adotar as normas internacionais. Ou seja, ainda que se guarde relação entre as práticas legais com o arcabouço que orienta a prática jurídica de cada país, e até mesmo em certa medida a prática contábil, a adoção desses países às normas internacionais de contabilidade faz com que a interferência legal/fiscal sobre as práticas contábeis diminuam ou até se anule a ponto de haver de fato uma prática contábil calcada em princípios.

\subsubsection{Análise de Sensibilidade e Robustez}

Em primeiro lugar, é possível que o Modelo 3 apresente problemas de endogeneidade, devido à simultaneidade das variáveis GR e CFF. Especificamente, a variável CFF é desenvolvida a partir da REQM do Modelo 2, o qual utiliza os accruals discricionários como variável explicativa. Igualmente, a variável GR é construída com base no ranking dos accruals discricionários absolutos. Isto é, há gerenciamento de resultados nos dois lados da regressão. Levando em conta essa possibilidade, apresenta-se as seguintes evidências para validar a robustez nesse ponto:

O coeficiente de determinação estimado no estudo foi, aproximadamente, 0,58, e para Gujarati e Porter (2011), o coeficiente de determinação é considerado alto quando este for superior a 0,8.

Em análise não tabulada, foi verificado que a correlação entre as variáveis GR e CFF foi de -0,27, cujo valor está abaixo do que sugere Gujarati e Porter (2011).

Uma outra evidência de endogeneidade seria a falta de significância de um ou mais coeficientes ao se incluir a variável CFF. Nesse sentido, realizou-se a estimação sem a referida variável, e a única mudança que houve foi no termo de interação $S L^{*} C F F$, que passou a ser significativo. Contudo, isso pode ser interpretado como algo natural por se tratar de uma variável de interação.

Porém, é fato que o modelo apresentou problemas de autocorrelação e, para tanto, o modelo foi estimado aplicando-se a clusterização, que estima erros-padrão robustos mesmo na presença de autocorrelação e heterocedasticidade. Portanto, em relação ao possível efeito feedback em virtude das variáveis GR e CFF, acredita-se que não esteja trazendo viés para os resultados estimados.

Em segundo lugar, considerando a falta de normalidade dos resíduos e a presença de outliers, optou-se por executar o modelo com regressão quantílica, cujo método é robusto para distribuições não normais e pouco sensível a outliers (Duarte, Girão, \& Paulo, 2017).

Nesse sentido, realizou-se as regressões do Modelo 3 com quantis iguais a 0,25, 0,50 e 0,75, de modo a avaliar o efeito das variáveis independentes em países com baixo, mediano e alto índice de gerenciamento de resultados, respectivamente. Com isso, foi verificado que as variáveis e os sinais obtidos em todos os quantis foram semelhantes aos resultados alcançados por meio do método de MQO.

Isto é, o nível de conformidade financeira e fiscal (CFF), o desenvolvimento do mercado de capitais (DMC) e a interação entre a adoção das IFRS e a CFF (IFRS*CFF) foram estatisticamente significantes e mantiveram o sinal, apesar de algumas dessas variáveis terem apresentado maior significância em determinados quantis.

Ademais, nos quantis de mediano e baixo gerenciamento de resultados, verificou-se que outras variáveis (SL*CFF, ILEG e IFRS) também apresentaram significância estatística. Entretanto, em países com maior índice de gerenciamento de resultados (quantil =0,75), as variáveis e sinais que se mostra- 
ram significantes foram iguais aos obtidos pela regressão com MQO. Portanto, é possível concluir que os resultados são robustos, mesmo que se utilize outro método de estimação.

Por fim, ao se considerar a heterogeneidade dos mercados de capitais, optou-se por excluir alguns países, a fim de analisar se os resultados obtidos não são influenciados por algum(ns) deles. Assim, levando em consideração a Tabela 1, foram verificados os países que tinham mais ou menos um desvio-padrão da média de empresas listadas nas Bolsas, o que levou a exclusão dos seguintes países: Austrália, China, EUA, Índia e Japão.

Posteriormente, os índices de gerenciamento de resultados e de conformidade financeira e fiscal foram reconstruídos sem os países citados, e a regressão foi estimada novamente. Desse modo, constatou-se que os sinais e o nível de significância das variáveis CFF, DMC e IFRS*CFF permaneceram inalterados. Contudo, a variável ILEG passou a deter significância estatística, indicando que países com maior imposição legal gerenciam menos os resultados, ou seja, indo ao encontro dos resultados já observados na seção anterior, bem como a literatura que a suporta (e.g. Frank, Lynch e Rego, 2009; Tang, 2014).

Portanto, é possível concluir que os resultados são consistentes mesmo com a ausência de normalidade dos resíduos (o que demonstra a aplicabilidade do Teorema do Limite Central no estudo) e com a heterogeneidade dos países (outliers).

\section{CONSIDERAÇÕES FINAIS}

O objetivo do estudo foi analisar o impacto da conformidade financeira e fiscal exigida nos países sobre o nível de gerenciamento de resultados por meio de accruals, levando em consideração países common e code law do G-20.

Nesse sentido, os resultados demonstraram uma relação negativa entre o nível de CFF e o índice de GR nos países, consistente com a hipótese H1a . Isto é, a exigência de maior conformidade entre as normas fiscais e financeiras nos países limita a prática de gerenciamento de resultados. Logo, esse resultado apoia o entendimento de que ao elevar a conformidade, os gestores têm sua discricionariedade reduzida e os custos do gerenciamento aumentados.

Contudo, os resultados também expressam a importância de se considerar fatores institucionais antes de se avaliar o impacto da CFF sobre o GR. Especificamente, as evidências demonstram que o efeito da conformidade sobre o GR difere entre países-anos que realizaram ou não a convergência, sendo que, em países-anos que adotaram as IFRS, a elevada CFF foi associada a um aumento no índice de gerenciamento de resultados.

Portanto, é possível concluir que o nível de CFF exigido em um país pode influenciar a prática de GR das empresas, mas que essa relação pode diferir em decorrência de algumas características institucionais.

A pesquisa contribui com a literatura de GR e de CFF, à medida que apresenta a influência dessa sobre aquela. Além disso, é relevante para os órgãos normatizadores e reguladores responsáveis por estabelecer normas contábeis/fiscais, pois demonstra o efeito que a proximidade entre o lucro contábil e o tributável gera sobre o nível de GR dentro do país. Por fim, também é importante para a tomada de decisões de investidores, pois mostra que o nível de CFF exigido em um país pode afetar a qualidade das informações reportadas a eles.

Contudo, o estudo é limitado pelo próprio modelo de GR, uma vez que os resíduos podem estar sendo inflados devido à omissão de variáveis, e pela existência de multicolinearidade, que não pôde ser corrigida. Também, outra limitação é a simplificação na classificação dos sistemas legais e o fato dessa ser mais jurídica do que contábil e ter sido baseada em um estudo não tão atual. Ainda, a pesquisa é 
limitada pela falta de atualização monetária das variáveis e pela desproporção entre países de sistemas common e code law, além da falta de controle sobre os incentivos fiscais, que pode influenciar as medidas de GR e CFF

Por fim, outra limitação é a desconsideração da forma com que a informação nasce (contábil ou fiscal), já que o estudo só considerou a proximidade/distanciamento entre o lucro contábil e o tributável, e não observou em que sentido se dá os ajustes. Assim, sugere-se que pesquisas futuras examinem a relação entre CFF e GR, levando em conta o sentido da CFF. Além disso, também seria interessante que estudos futuros utilizassem outros modelos de gerenciamento de resultados conjuntamente, e que analisassem o impacto da conformidade financeira e fiscal sobre outras proxies da qualidade do lucro, além do GR.

\section{REFERÊNCIAS}

Afshartous, D., \& Preston, R. A. (2011). Key results of interaction models with centering. Journal of Statistics Education, 19(3). DOI: 10.1080/10691898.2011.11889620

Ahmed, A. S., Neel, M., \& Wang, D. (2013). Does mandatory adoption of IFRS improve accounting quality? Preliminary evidence. Contemporary Accounting Research, 30(4), 1344-1372. DOI: 10.1111/j. 1911-3846.2012.01193.x

Ali, A., \& Hwang, L. S. (2000). Country-specific factors related to financial reporting and the value relevance of accounting data. Journal of accounting research, 38(1), 1-21. DOI: 10.2307/2672920

Atwood, T. J., Drake, M. S., \& Myers, L. A. (2010). Book-tax conformity, earnings persistence and the association between earnings and future cash flows. Journal of Accounting and Economics, 50(1), 111-125. DOI: 10.1016/j.jacceco.2009.11.001

Ball, R., Kothari, S. P., \& Robin, A. (2000). The effect of international institutional factors on properties of accounting earnings. Journal of accounting and economics, 29(1), 1-51. DOI: 10.1016/S01654101(00)00012-4

Barth, M. E., Landsman, W. R., \& Lang, M. H. (2008). International accounting standards and accounting quality. Journal of accounting research, 46(3), 467-498. DOI: 10.1111/j.1475-679X.2008.00287.x

Benston, G. J., Bromwich, M., \& Wagenhofer, A. (2006). Principles-versus rules-based accounting standards: the FASB's standard setting strategy. Abacus, 42(2), 165-188.DOI: 10.1111/j.1467-6281.2006.00196.x

Blaylock, B., Gaertner, F., \& Shevlin, T. (2015). The association between book-tax conformity and earnings management. Review of Accounting Studies, 20(1), 141-172. DOI: 10.1007/s11142-014-9291-x

Brooks, C. (2014). Introductory Econometrics for Finance. 3.ed. New York: Cambridge University Press.

Brown, L. D., \& Higgins, H. N. (2005). Managers' forecast guidance of analysts: International evidence. Journal of Accounting and Public Policy, 24(4), 280-299. DOI: 10.1016/j.jaccpubpol.2005.05.001

Burgstahler, D. C., Hail, L., \& Leuz, C. (2006). The importance of reporting incentives: Earnings management in European private and public firms. The accounting review, 81(5), 983-1016. DOI: 10.2308/ accr.2006.81.5.983

Chen, X., Lee, C. W. J., \& Li, J. (2008). Government assisted earnings management in China. Journal of Accounting and Public Policy, 27(3), 262-274. DOI: 10.1016/j.jaccpubpol.2008.02.005

Choi, F. D. \& Meek, G. K. (2011). International accounting. Pearson Higher Ed. 
Costa, P. D. (2012). Implicações da adoção das IFRS sobre a conformidade financeira e fiscal das companhias abertas brasileiras. Tese de Doutorado em Contabilidade, Universidade de São Paulo, São Paulo, Brasil.

Desai, M. A. (2005). The degradation of reported corporate profits. Journal of Economic Perspectives, 19(4), 171-192. DOI: 10.1257/089533005775196705

Duarte, F. C. L, Girão, L. F. A. P, Paulo, E. (2017). Avaliando Modelos Lineares de Value Relevance: Eles Captam o que Deveriam Captar? RAC-Revista de Administração Contemporânea, 21, 110-134. DOI: 10.1590/1982-7849rac2017160202

Frank, M. M., Lynch, L. J., \& Rego, S. O. (2009). Tax reporting aggressiveness and its relation to aggressive financial reporting. The Accounting Review, 84(2), 467-496. DOI: 10.2308/accr.2009.84.2.467

Guenther, D. A., \& Young, D. (2000). The association between financial accounting measures and real economic activity: A multinational study. Journal of Accounting and Economics, 29(1), 53-72.DOI: 10.1016/ S0165-4101(00)00013-6

Gujarati, D. N. \& Porter, D. C. (2011). Econometria Básica. (5.ed.) Porto Alegre: AMGH.

Hanlon, M., Laplante, S. K., \& Shevlin, T. (2005). Evidence for the possible information loss of conforming book income and taxable income. The Journal of Law and Economics, 48(2), 407-442. DOI: 10.1086/497525

Hanlon, M., Maydew, E. L., \& Shevlin, T. (2008). An unintended consequence of book-tax conformity: A loss of earnings informativeness. Journal of Accounting and Economics, 46(2), 294-311.DOI: 10.1016/j. jacceco.2008.09.003

Hanlon, M., \& Shevlin, T. (2005). Book-tax conformity for corporate income: An introduction to the issues. Tax policy and the economy, 19, 101-134. DOI: 10.1086/tpe.19.20061897

Kajimoto, C. G. K., \& Nakao, S. H. (2018). Persistência do Lucro Tributável com a Adoção das IFRS no Brasil. Contabilidade Vista \& Revista, 29(1), 130-149. DOI: 10.22561/cvr.v29i1.4057

Kothari, S. P., Leone, A. J., \& Wasley, C. E. (2005). Performance matched discretionary accrual measures. Journal of accounting and economics, 39(1), 163-197. DOI: 10.1016/j.jacceco.2004.11.002

Lamb, M., Nobes, C., \& Roberts, A. (1998). International variations in the connections between tax and financial reporting. Accounting and Business Research, 28(3), 173-188. DOI: 10.1080/00014788.1998.9728908

La Porta, R.., Lopez-de-Silanes, F., Shleifer, A., \& Vishny, R.W. (1998). Law and finance. Journal of political economy, 106(6), 1113-1155. DOI: 10.1086/250042

Leuz, C., Nanda, D., \& Wysocki, P. D. (2003). Earnings management and investor protection: an international comparison. Journal of financial economics, 69(3), 505-527. DOI: 10.1016/S0304-405X(03)00121-1

Martinez, A. L. (2013). Earnings management in Brazil: a survey of the literature. Brazilian Business Review, 10(4),01-29. DOI: 10.15728/bbr.2013.10.4.1

Martins, E., Martins, V. A., \& Martins, É. A. (2007). Normatização contábil: ensaio sobre sua evolução e o papel do CPC. Revista de Informação Contábil, 1(1), 7-30.

Niyama, J. K., Costa, P. D. S., \& Aquino, D. R. B. (2005). Principais causas das diferenças internacionais no financial reporting: uma pesquisa empírica em instituições de ensino superior do nordeste e centro-oeste do Brasil. ConTexto, 5(8), 01-22.

Niyama, J. K., Rodrigues, A. M. G., \& Rodrigues, J. M. (2015). Algumas reflexões sobre contabilidade criativa e as normas internacionais de contabilidade. Revista Universo Contábil, 11(1), 69-87. DOI: 10.4270/ ruc.2015104 
Schipper, K. (2003). Principles-based accounting standards. Accounting horizons, 17(1), 61-72. DOI: 10.2308/acch.2003.17.1.61

Tang, T.Y. (2005). Book-tax differences, a proxy for earnings management and tax management-empirical evidence from China. Available at SSRN 872389.

Tang, T.Y. (2014). Does book-tax conformity deter opportunistic book and tax reporting? An international analysis. European Accounting Review, 24(3), 441-469. DOI: 10.1080/09638180.2014.932297

Tran, A.; Yu, Y.H. (2008). Effective Tax Rates of Corporate Australia and the Book-Tax Income Gap. Australian Tax Forum, 23(3),233-268.

Watrin, C., Ebert, N., \& Thomsen, M. (2014). Book-tax conformity and earnings management: insights from European one-and two-book systems. The Journal of the American Taxation Association, 36(2), 55-89. DOI: 10.2308/atax-50769

Yoon, S.W. (2008). An international study of the relation between book-tax conformity and the value relevance of earnings components. Journal of International Business Research, 7(2), 31-56. 